\title{
Parent-youth discordance about youth-witnessed violence: Associations with trauma symptoms and service use in an at- risk sample
}

\author{
Terri Lewis $^{\mathrm{a}}$, Richard Thompson ${ }^{\mathrm{b}}$, Jonathan B. Kotch ${ }^{\mathrm{C}}$, Laura J. Proctor ${ }^{\mathrm{d}}$, Alan J. \\ Litrownik $^{\mathrm{e}}$, Diana J. English ${ }^{\dagger}$, Desmond K. Runyan ${ }^{g}$, Tisha R. Wiley ${ }^{b}$, and Howard \\ Dubowitz $^{\mathrm{h}}$ \\ aUniversity of Alabama at Birmingham, Birmingham, AL, USA \\ bJuvenile Protective Agency \\ 'University of North Carolina at Chapel Hill, Chapel Hill, NC, USA \\ dJudge Baker Children's Center, Harvard Medical School, Cambridge, MA, USA \\ eSan Diego State University, San Diego, CA, USA \\ fUniversity of Washington, Seattle, WA, USA \\ 9The Kempe Children's Center, Department of Pediatrics, University of Colorado School of \\ Medicine, Denver, CO, USA \\ hUniversity of Maryland School of Medicine, College Park, MD, USA
}

\begin{abstract}
Objective-Studies have consistently demonstrated a lack of agreement between youth and parent reports regarding youth-witnessed violence. However, little is known about whether disagreement is associated with poorer outcomes and less utilization of mental health services. The purpose of the current study was to examine disagreement among youth and parents about youth witnessed violence, and determine whether concordance predicted trauma symptoms and recognition of need and receipt of counseling services.
\end{abstract}

Methods-Concordance about youth-witnessed violence was examined in 766 dyads from the Longitudinal Studies of Child Abuse and Neglect (LONGSCAN). Youth participants self-reported trauma symptoms, caregivers indicated youth need for and receipt of services. Both youth and parents provided information about youth-witnessed violence exposure in the last year.

Results-Results showed youth and caregivers differed significantly about youth-witnessed violence. Specifically, $42 \%$ of youth reported youth-witnessed violence, compared to only $15 \%$ of parents. For those parents who reported youth-witnessed violence, only $29 \%$ reported an identified need for services and only $17 \%$ reported the youth had received any mental health services. Concordance between parent-youth dyads was associated with greater identified need for services but was not associated with the use of counseling services or trauma symptoms.

(c) 2012 Elsevier Ltd. All rights reserved

Corresponding author address: Department of Health Behavior, School of Public Health, University of Alabama at Birmingham, RPHB 227, $15303^{\text {rd }}$ Avenue S., Birmingham, AL 35294-0022, USA.

Publisher's Disclaimer: This is a PDF file of an unedited manuscript that has been accepted for publication. As a service to our customers we are providing this early version of the manuscript. The manuscript will undergo copyediting, typesetting, and review of the resulting proof before it is published in its final citable form. Please note that during the production process errors may be discovered which could affect the content, and all legal disclaimers that apply to the journal pertain. 
Conclusions-Youth who reported witnessing violence reported more frequent trauma symptoms regardless of concordance. Parents from dyads in which both informants reported youth-witnessed violence were more likely to endorse need for, but not receipt of counseling services. Given this association between youth-witnessed violence and mental health problems, more work is needed to identify barriers to concordance as well as service utilization.

\section{Keywords}

youth; witnessed-violence; concordance; trauma; mental health services

\section{Introduction}

Youth exposure to violence is a significant public health problem. Using a large, nationally representative sample of adolescents, Zinzow and colleagues (2009) estimated the prevalence of youth exposure to parental and community violence to be $9 \%$ and $38 \%$ respectively. Similarly, Finkelhor and colleagues reported that nearly one in four children had witnessed the victimization of another person in the past year (Finkelhor, Ormrod, Turner, \& Hamby, 2009). Higher prevalence rates are reported for those living in urban or impoverished areas (Miller, Wasserman, Neugebauer, Gorman-Smith, \& Kamboukos, 1999) and for high-risk populations such as maltreated children (Edleson, 1999; Finkelhor, Ormrod, Turner, \& Hamby, 2005; O'Leary, Smith-Slep, \& O'Leary, 2000; Osofsky, 2003). Witnessing violence has been associated with both short- and long-term negative outcomes including trauma symptoms, internalizing behaviors, externalizing behaviors, aggressive behavior, delinquency, adult criminal behavior, suicidal ideation, and health risk behaviors (Cooley-Strickland et al., 2009; Fowler, Tompsett, Braciszewski, Jacques-Tiura \& Baltes, 2009; Holt, Buckley, \& Whelan, 2008; Lewis et al., 2011; Manly, Kim, Rogosch, \& Cicchetti 2001; Jones et al., 2010; Thompson et al., 2006; Thompson, Proctor, English, Narasimhan, \& Everson., 2012).

Prior research has revealed a lack of consistency between youth and parent reports about youth exposure to violence in both community and domestic settings (Ceballo, Dahl, Aretakis, \& Ramirez, 2001; Goodman, De Los Reyes, \& Bradshaw, 2010; Hill \& Jones, 1997; Howard, Cross, Li, \& Huang, 1999; Kuo, Mohler, Raudenbush, \& Earls, 2000; Lewis et al., 2010). In nearly every study, parents reported significantly fewer exposures than did youth; consequently, most examinations of informant discrepancies have focused on cases where youth report violence exposure and parents do not.

Discrepancies in parent and youth reports of youth-witnessed violence are problematic for several reasons. First, a lack of awareness regarding youth violence exposure may impair parents' ability to provide emotional support and coping skills, potentially leading to maladjustment in exposed youth (Goodman et al., 2010). Second, parents may also fail to make changes in the environment or parenting behavior to improve safety and reduce violence exposure. Finally, parents play a key role in determining whether youth receive mental health services (Srebnik, Cauce, \& Baydar, 1996). Their frequent failure to identify the need for services (Finkelhor, Wolak, \& Berliner, 2001; Guterman, Hahm, \& Cameron, 2006; Thompson et al., 2006) may be due, in part, to being unaware that youth in their care were exposed to violence. There is also some suggestion that discrepancy between youth and parent report may be related to problematic outcomes. In such cases, not only did youth evidence more behavioral difficulties when parents and youth did not agree about youth mental health symptoms (Ferdinand, van der Ende, \& Verhulst, 2006; Guion, Mrug, \& Windle, 2009), but were also less likely to have parents who were invested in their utilization of mental health services (Israel, Thomsen, Langeveld, \& Stormark, 2007). In short, parental lack of awareness of youth violence exposure is likely to result in missed 
opportunities to provide support, guidance, and access to services (Goodman, et al., 2010; Richters \& Martinez, 1993) that may subsequently result in greater youth maladjustment. However, no study to date has examined whether youth-parent agreement about youthwitnessed violence results in greater identified need for or use of counseling services.

Studies examining maladjustment as a function of discordance have reported mixed findings. One study, conducted with an urban, economically disadvantaged sample of 4thand 5th-graders, found that greater mother-child agreement about community violence exposure was associated with fewer child post-traumatic stress symptoms and internalizing problems (Ceballo et al., 2001). Similarly, low concordance in parent-youth dyads was associated with greater youth distress in a sample of urban, African-American youth aged 9 to 15 years (Howard et al., 1999). In contrast, Hill and Jones (1997) found no differences in the level of 9- to 12-year-old children's anxiety scores for those parent-child dyads that agreed about child witnessed community violence versus those who disagreed. As a whole, the generalizability and interpretability of this handful of studies is limited by small sample sizes and a focus on urban environments.

An additional limitation of prior research on consequences of discrepant reports of youth witnessing is that only one specific type of discrepancy has typically been examined---that in which parents reported less youth violence exposure than did youth. However, four possible permutations of concordance exist including agreement that youth-witnessed violence did not occur, and those cases where the parent but not the youth reported youthwitnessed violence. Examining all permutations of concordance may contribute to our understanding of whether consequences of disagreement vary among these four possible types.

Using a large multi-site sample of high-risk youth and their primary caregiver, the objectives of the current study were to examine (1) whether there is a significant difference between youth and caregiver report of youth witnessed violence, (2) to determine if there are differences among concordance groups in predicting youth-reported trauma symptoms, and (3) whether concordance group predicts identified need for and receipt of counseling services. We expect that youth and caregivers will disagree with respect to youth-witnessed violence, with youth reporting more violence compared to caregivers. However, given the lack of research on outcomes of parent-youth (dis)agreement, directional hypotheses are not made with respect to trauma symptoms or identified need for/use of services. Current theories suggest that parents who are aware of their youth's exposure to violence may provide important supportive mechanisms and reduce negative outcomes, such as trauma symptoms. In contrast, parents and youth who agree about youth violence exposure may do so given the severity and/or frequency of the violence exposure, thus exhibiting greater trauma symptoms. Concordance among youth and parents may result in greater identified need for and receipt of mental health services.

\section{Methods}

Data for these analyses were drawn from the Longitudinal Studies of Child Abuse and Neglect (LONGSCAN), a consortium of prospective studies of the antecedents and consequences of child maltreatment. LONGSCAN is comprised of five study sites distributed across the United States and a Coordinating Center. All sites share common instruments and protocols for data collection, entry, and management. Collectively, the site samples represent a continuum of maltreatment risk and experiences from participants notreported but at high-risk for maltreatment to severe maltreatment resulting in out of home placement. Children were considered at high risk of maltreatment at age 4 due to medical problems such as failure to thrive in the first two years of life, parental factors such as HIV 
infection or prenatal drug use, and sociodemographic factors such as poor social support and low SES. Detailed information regarding the samples and study design is available in Runyan et al. (1998).

LONGSCAN staff conducted face-to-face interviews with the study participants and their primary caregivers (referred to hereafter as 'parents') every 2 years, beginning when the children were 4 years of age. Data for the current analyses were collected when the youth participants were approximately 12 years of age. The youth and his/her parent completed separate Audio-Computer Assisted Self-administered Interviews (A-CASI). A trained interviewer facilitated the interviews and administered the few measures that were not selfadministered. Data from both the youth and the parent were used for the current analyses. Parents provided consent for their own participation as well as for the participation of their youth; the youth provided their assent to participate. All sites and the LONGSCAN Coordinating Center received approval from their respective institutional review boards to conduct the study.

\section{Participants}

The LONGSCAN baseline sample included 1,354 child-parent dyads. At the age 12 interview, 794 dyads had complete data on all measures of interest. Twenty-eight participants were in some sort of foster-care placement at the age 12 interview. Because foster-parents may not know the youth's history of violence exposure, data for these 28 participants were dropped from the analysis sample. Of the remaining 766 dyads, youth gender was equally distributed. A majority were African American (55\%). The average age of the youth was 12.4 years $(\underline{S D}=.44$; range $11.0-13.8)$. The majority of parent respondents were female (93\%). Sixty-nine percent of parent respondents were a biological parent, followed by adoptive mother (10\%), grandmother $(8 \%)$, or other relative $(13 \%)$. Fifty-one percent of the dyads were of the same sex. The median annual household income was between $\$ 20,000$ and $\$ 24,999$. The analysis sample and the LONGSCAN baseline sample did not differ with respect to youth gender or race/ethnicity.

\section{Measures}

Witnessed violence: Youth report-Youth report of witnessed violence was assessed using the History of Witnessed Violence measure (LONGSCAN, 1998). This measure was developed by LONGSCAN, based on other measures of witnessed violence (e.g., Richters \& Martinez, 1990). The scale consisted of 8 items ranging in severity from witnessing an arrest to witnessing someone killed. Each endorsement of a witnessed event elicited follow-up questions that included how often the event was witnessed ever and in the last year. Response options were: 0 (never), 1 ( 1 time), 2 (2-3 times), and 3 ( 4 or more times.

Witnessed violence: Parent report-Parents completed the Child's Life Events scale (LONGSCAN, 1992), a project adaptation of the Life Event Record (Coddington, 1972). LONGSCAN investigators added six items assessing child/youth exposure to violence. The items were similar to the youth History of Witnessed Violence items with a few minor exceptions. First, the parent received one item not administered to the youth respondents ("heard long, loud arguments between family members"), and the youth respondents received one item not administered to parents ("seen someone arrested"). Second, there were minor variations in phrasing between the two respondent versions. For example, the youth version asked, "Have you ever seen someone being slapped, kicked, hit with something, or beaten up?", whereas the parent version asked, "Did s/he see anyone getting hit, kicked, or physically harmed in some other way?" Third, the parent version combined some specific acts into single questions (e.g., "Did child see anyone get shot or stabbed?") whereas the youth version assessed each act separately. Also, the parent version referenced events 
witnessed 'in the last year' whereas the youth respondent version referenced both 'ever' and 'in the last year'. For the current study, only reports of events witnessed 'in the last year' were used. Only items common to both respondents and assessed over the same time frame were included in examining concordance between parent and youth reports.

Any endorsement of any item was dichotomized; witnessing any event with any frequency in the last year was coded ' 1 ' and no witnessing of any event was coded ' 0 '. Inter-item reliability of the dichotomized items, as assessed by Cronbach's alpha, for the youth and parent were .67 and .45 respectively. Lewis et al., (2010) found that a dichotomized variable for witnessed violence using youth and parent informants was significantly predictive of externalizing and internalizing behaviors in youth. This suggests good criterion validity despite the modest inter-item agreement. Agreement within the dyad about youth-witnessed violence (YWV) was coded into one of four mutually exclusive groups (hereafter referred to as 'concordance groups'): (1) neither respondent reported YWV (Neither Report), (2) both respondents reported YWV (Both Report), (3) the parent, but not the youth, reported YWV (Parent Only), and (4) youth, but not the parent reported YWV (Youth Only). See Table 1 for the distribution of demographic variables by concordance group.

Trauma symptoms-Youth respondents completed the Trauma Symptom Checklist for Children (TSC-C; Briere, 1996). Respondents indicated the frequency with which each of 54 statements applied to them on a 4-point scale ranging from 0 (never) to 3 (almost always). Responses were summed within each of the 6 clinical scales (Anxiety, Anger, Depression, Post Traumatic Stress (PTS), Dissociation, and Sexual Concerns) and divided by the number of items for each scale. Higher scores indicate more frequent trauma symptoms. The clinical scales have good internal consistency and reliability (Briere, 1996). For the current analyses, raw scores from the Anger, Anxiety, Depression, and PTS scales were examined. Cronbach alphas for the 4 scales were good, ranging from .82 to .87 .

Demographic variables-Demographic information on youth race/ethnicity and gender was obtained during the baseline interview from the parent. Race was dischotomized as Minority (non-White) or White.

History of child maltreatment-History of child maltreatment was assessed via review of Child Protective Service (CPS) records and youth self-reports of physical abuse, sexual abuse, and psychological abuse. CPS case narratives for allegations of abuse and/or neglect were abstracted and coded according to a system developed by Barnett and colleagues (Barnett, Manly, \& Cicchetti, 1993) and modified by the LONGSCAN group (English \& LONGSCAN Investigators, 1997). Abstractors were trained to a minimal standard of $90 \%$ agreement with a 'gold standard coder' prior to independent coding of CPS data. Ongoing evaluation of reliability showed good agreement between raters with Kappas for abuse type ranging from .73 to .88 . Any allegation to CPS for physical, sexual, emotional abuse, or neglect was coded as a history of child maltreatment in the current study.

In addition to CPS records, three project-developed measures were administered to the youth at age 12 to assess possible lifetime experience of these types of abuse (Self-report of Physical Abuse, Self-report of Sexual Abuse, and Self-report of Psychological Abuse; LONGSCAN 1998). Each instrument contains stem questions addressing specific abuse experiences. For the purposes of this study, responses from 15 physical abuse items, 11 sexual abuse items, and 18 psychological abuse items were used to create an overall dichotomous indicator for whether youth reported any abuse. 
For the current analyses, if the youth had been the subject of any CPS report for any maltreatment (including neglect) from birth to age 12 or if the youth self-reported any abuse, then $\mathrm{s} / \mathrm{he}$ was considered to have been maltreated.

Youth counseling services need and receipt-A project-developed measure was used to assess receipt of a variety of services provided to either the youth or parent (Service Utilization; LONGSCAN, 1998). Parent-identified need for, and receipt of youth counseling services were of interest for the current study. In a set of branching items, parents indicated whether, in the last year, the youth needed any type of counseling or therapy, outside of school, for a psychological or behavioral problem. If the parent responded 'yes' s/he was asked whether the youth had received any psychological services. If the respondent indicated that the youth needed services, then need for services was coded ' 1 ', no indicated need was coded as ' 0 '. If the parent endorsed that the youth had received services, services receipt was coded as ' 1 '. If the respondent indicated no services were needed or received, then services receipt was coded as ' 0 '.

\section{Statistical analyses}

Three sets of analyses were conducted. First to test whether there is significant disagreement between youth and parents, we conducted a McNemar's test for paired data to compare youth and parent reports of YWV. Second, we conducted four sets of Ordinary Least Squares (OLS) regression analyses to examine whether concordance groups predicts the four types of trauma symptoms, controlling for youth gender, race/ethnicity status, maltreatment, and study site. Third, we conducted two sets of logistic regression analyses to examine whether concordance group predicts (1) endorsed need for counseling services and (2) endorsed receipt of counseling services. A simultaneous estimation procedure was used for both the OLS and logistic regression analyses. Because victims of child maltreatment are often at higher risk of violence exposure (Hamby, Finkelhor, Turner, \& Ormrod, 2010) and exhibit more trauma symptoms than nonmaltreated children, a history of child maltreatment was included as a control variable. All analyses were conducted in SAS V9.2.

\section{Results}

\section{Youth-parent discord about YWV}

Forty-one percent of youth $(n=317)$ reported having witnessed 1 or more events compared to only $15 \%(\mathrm{n}=115)$ of parents. To examine whether this difference was significant, McNemar's test for paired data was conducted and revealed a significant difference in reporting among informants $\left[\chi^{2}(1, N=766)=129.1, \underline{p}<05\right]$. Among the dyads, $59 \%$ of youth and parents provided consistent reports with $51 \%$ of the dyads reporting that no violence had been witnessed (Neither Report) and 8\% reporting that violence had been witnessed (Both Report). The remaining $41 \%$ of dyads provided inconsistent reports, which included youth who endorsed witnessing violence but their parents did not (34\%, Youth Only), and parents who reported YWV but the youth did not (7\%, Parent Only).

\section{Trauma symptoms and concordance group}

To examine whether concordance group predicts anger, anxiety, post-traumatic stress, and depression scores from the TSC-C, four multivariate regression analyses were conducted controlling for study site, gender, race/ethnicity, and history of child maltreatment. Table 2 presents the scores on the four trauma symptom scales for each concordance group. Findings presented in Table 3 indicate that youth-reported trauma symptoms on all scales were higher among the Both Report and Youth Only groups compared to the Neither Report group. Scores in the groups with no youth-reported witnessed violence (Parent Only, Neither Report) did not differ significantly from one another in any model. With regard to control 
variables, gender was associated with several outcomes: girls reported higher anxiety, depression, and PTS symptoms (all $\mathrm{p}<.05$ ). A history of maltreatment was associated with higher scores on all four trauma symptom scales (all $\mathrm{p}<.05$ ).

Because studies examining concordance have typically compared dyads in which both informants report YWV and those in which only the youth reported YWV, additional analyses were conducted with the Both Report group serving as the reference group. Findings replicated those presented above, such that there were no differences between the Both Report group and the Youth Only group for any of the four trauma symptom scales.

\section{Concordance groups and youth counseling services need and receipt}

To examine whether concordance groups predicts youth counseling services need and receipt, two logistic regression models were conducted controlling for study site, race/ ethnicity, gender, and history of child maltreatment. Overall, $21 \%$ of parents reported that the youth needed counseling services in the last year, and $16 \%$ reported that the youth had received counseling services in the last year. See Table 2 for the frequency distribution of need for and receipt of counseling services across groups. Table 4 displays the results from the two logistic regression analyses showing significant difference among concordance groups for need for services. Specifically, parents in the Both Report group were twice as likely to report need for services compared to parents in the Neither Report group (OR=2.0; CI: 1.3, 4.4). The receipt of services was not related to concordance group (all $\mathrm{p}$ values > 05). A history of child maltreatment significantly predicted both need for services and receipt of service. The models for service need and service receipt correctly classified $66 \%$ and $63 \%$ of cases respectively.

\section{Summary}

Youth reported more witnessed violence than parents. Trauma symptoms differed significantly among the groups. Youth in dyads in which both informants reported YWV (Both Report) and where the youth but not parents reported YWV (Youth Only) reported more trauma symptoms; this suggests that youth reported witnessed violence was associated with more frequent trauma symptoms regardless of whether the parent reported youth violence exposure. Group membership was related to parent reports of youth need for counseling services, but not to the receipt of services.

\section{Discussion}

This study extends prior work on youth violence exposure by examining whether concordance is associated with fewer trauma symptoms and greater identified need for or receipt of services. Utilizing data from a larger, more diverse sample of youth than prior studies, we examined (1) a theoretically proposed, but empirically unexamined, relationship between concordance and service use and (2) outcomes of all possible combinations of concordance or agreement including instances in which both informants agreed that no violence had occurred as well as those dyads in which only the parent reported youthwitnessed violence. Consistent with a growing body of literature (Ceballo, et al., 2001; Hill \& Jones, 1997; Kuo et al., 2000; Lewis et al., 2010; Litrownik, Newton, Hunter, English, \& Everson, 2003; Mahoney, Donnelly, Boxer, \& Lewis, 2003), our findings indicate that parents significantly under reported youth-witnessed violence. Despite speculation that dyads in which the parent, but not the youth, would report youth-witnessed violence would be rare (Goodman et al., 2010), we found that this form of discrepancy was nearly as prevalent as agreement between the dyads that violence exposure had occurred. 
Of the $41 \%$ of youth who reported witnessing violence, parents identified a need for counseling services for only $22 \%$ and receipt of services for only $14 \%$. Of the parents who reported youthwitnessed violence, $29 \%$ identified a need for services with only $17 \%$ reporting use of services. Trauma symptoms, on all scales, were highest among the youthreported witnessed violence groups regardless of whether the parent also reported the exposure. Clinical and theoretical literature highlights the importance of parent knowledge about youth violence exposure as a method of engagement for resources both within and outside the parent-child/family context, including mental health services. The findings from the current study suggest parent endorsed need for services was more likely when youthwitnessed violence was endorsed by both informants. However, receipt of counseling services was no more likely among dyads who agreed that youth-witnessed violence had occurred.

Somewhat consistent with this, Guterman and colleagues (2002) found youth-reported violence exposure resulted in lower odds of receiving services. Because parents are often the gate-way to obtaining services, it is important to know what factors may impede service utilization. Perhaps in those cases where the violence is occurring in the home, parents are less likely to seek formal services due to concerns about the disclosure of in-home violence. Alternatively, because youth violence exposure may also be associated with the youth's own delinquent activities, perhaps there is concern about the implications of the youth's culpability in violent events. Additionally, it could be that those living in violent neighborhoods have come to regard such exposure as normative and less likely to identify the consequences or mental health needs of their children (Hill \& Jones, 1997). Finally, perhaps parents may identify the need for services, but perceive such services to be ineffective. It would be informative to extend this examination further to understand what factors may impede formal service utilization or whether the context in which the violence is occurring plays a role in whether the parent seeks mental health services for the exposed youth.

In contrast to theoretically based hypotheses that concordance between parents and youth about youth-violence exposure is a protective factor in reducing maladjustment (Goodman et al., 2010), we did not find fewer trauma symptoms in the group where both informants reported youth-witnessed violence than the group in which only the youth reported violence exposure. As expected, trauma symptoms were lowest in the group in which neither informant reported youthwitnessed violence. Interestingly, trauma symptoms in the Parent Only group were not significantly higher than the Neither group. Youth reports of witnessed violence were associated with more trauma symptoms, but parent concordance about youthwitnessed violence did not appear to be protective or minimize the effects of violence exposure. Although not significant, trauma scores were slightly higher in the group in which both informants endorsed youth-witnessed violence than the Youth Only group. This may suggest that violence exposure may be severe or prevalent enough that parents are both aware of the exposure and the impact on youth. It is this group of parents that are also more likely to endorse need for counseling services than any other group.

There were some limitations in our examination of concordance and consequences not previously mentioned. First, we did not assess whether same sex parent-youth dyads were more concordant than opposite sex dyads. In this sample, $93 \%$ of the parent respondents were female, significantly limiting our ability to assess parent-youth gender differences between groups due to small cell sizes. Second, we did not ask about youth disclosure of witnessed violence to their parent, a potentially important factor in reducing inconsistency between informants (Goodman et al., 2010). Third, our assessment of receipt of counseling services was limited to those respondents who endorsed a need for services for a psychological or behavioral problem, and we did not assess whether the youth was receiving 
counseling services in the school. Thus, we may have underestimated the number of youth receiving services. In addition, it is possible that parents may not have accurately reported or recalled possible services received. Fourth, individual items about youth-witnessed violence included slight deviations in wording and items and thus were not identical for both informants. However, our findings that youth report more witnessed violence than parents is consistent with the vast majority of literature reporting discrepancies among informants. Fifth, all of the data used for these analyses were collected at the same time (i.e., youth age 12), limiting causal interpretation. Finally, the LONGSCAN sample represents a sample of maltreated youth or those who were at high risk for maltreatment prior to age 4 . Thus, results may not generalize to populations without such histories.

This study extends the limited body of literature about the potential outcomes of concordance among youth and parents about youth-witnessed violence. By expanding the examination to assess all possible combinations of agreement and disagreement, we found that situations in which the parent, but not the youth reported violence exposure was as prevalent as dyads who agreed that youth-witnessed violence had occurred. Of particular concern is the significantly higher rate of endorsement of witnessed violence and associated trauma symptoms among youth. Although parents who provided consistent reports about the occurrence of youth-witnessed violence were more likely to endorse a need for youth counseling services, they were no more likely to report receipt of counseling services. Future investigations should consider how concordance changes over time and what impact disagreement has at different developmental periods. As a whole, these findings highlight the need to better understand how to promote the prevention and recognition of youth violence exposure as well as facilitate engagement of mental health services for violenceexposed youth.

\section{Acknowledgments}

Funding for the Longitudinal Studies of Child Abuse and Neglect (LONGSCAN) was provided by a grant from the National Center on Child Abuse and Neglect, the Children's Bureau, Office of Child Abuse and Neglect Administration on Children, Youth, and Families.

\section{References}

Barnett, D.; Manly, JT.; Cicchetti, D. Defining child maltreatment: The interface between policy and research. In: Cicchetti, D.; Toth, SL., editors. Advances in applied developmental psychology: Child abuse, child development, and social olicy. Norwood, NJ: Ablex; 1993. p. 7-14.

Briere, J. Trauma Symptom Checklist for Children: Professional manual. Odessa, FL: Psychological Assessment Resources, Inc; 1996.

Ceballo R, Dahl TA, Aretakis MT, Ramirez C. Inner-city children's exposure to community violence: How much do parents know? Journal of Marriage and Family. 2001; 63:927-940.

Coddington RD. The significance of life events as etiological factors in the diseases of children-II. A study of normal population. Journal of Psychosomatic Research. 1972; 16:205-213. [PubMed: 5072914]

Cooley-Strickland M, Quille TJ, Griffin RS, Stuart EA, Bradshaw CP, Furr-Holden D. Community violence and youth: Affect, behavior, substance use, and academics. Clinical Child and Family Psychology Review. 2009; 12:127-156. [PubMed: 19472053]

Edleson JL. The overlap between child maltreatment and woman battering. Violence Against Women. 1999; 52:134-154.

English, DJ.; The LONGSCAN Investigators. Modified Maltreatment Classification System (MMCS). 1997. Unpublished manual. Retrieved from http://www.iprc.unc.edu/longscan/pages/mmcs/ LONGSCAN\%20MMCS\%20Coding.pdf

Ferdinand RF, van der Ende J, Verhulst FC. Prognostic value of parent-adolescent disagreement in a referred sample. European Journal of Child and Adolescent Psychiatry. 2006; 15:156-162. 
Finkelhor D, Ormrod R, Turner H, Hamby S. The victimization of children and youth: A comprehensive, national survey. Child Maltreatment. 2005; 10:5-25. [PubMed: 15611323]

Finkelhor D, Ormrod R, Turner H, Hamby S. Violence, abuse, and crime exposure in a national sample of children and youth. Pediatrics. 2009; 124:1-14. [PubMed: 19564276]

Finkelhor D, Wolak J, Berliner L. Police reporting and professional help seeking for child crime victims: A review. Child Maltreatment. 2001; 6:17-30. [PubMed: 11217166]

Fowler PJ, Tompsett CJ, Braciszewski JM, Jacques-Tiura AJ, Baltes BB. Community violence: A meta-analysis on the effect of exposure and mental health outcomes of children and adolescents. Development and Psychopathology. 2009; 21:227-259. [PubMed: 19144232]

Goodman KL, De Los Reyes A, Bradshaw CP. Understanding and using informants? reporting discrepancies of youth victimization: A conceptual model and recommendations for future research. Clinical Child and Family Psychological Review. 2010; 13:366-383.

Guion K, Mrug S, Windle M. Predictive value of informant discrepancies in reports of parenting: Relations to early adolescents' adjustment. Journal of Abnormal Child Psychology. 2009; 37:1730. [PubMed: 18584134]

Guterman NB, Hahm HC, Cameron M. Adolescent victimization and subsequent use of mental health counseling services. Journal of Adolescent Health. 2002; 30:336-345. [PubMed: 11996782]

Hamby S, Finkelhor D, Turner H, Ormrod R. The overlap of witnessing partner violence with child maltreatment and other victimizations in a nationally representative survey of youth. Child Abuse \& Neglect. 2010; 34:734-741. [PubMed: 20850182]

Hill H, Jones LP. Children's and parents' perceptions of children's exposure to violence in urban neighborhoods. Journal of the National Medical Association. 1997; 89(4):270-276. [PubMed: 9145632]

Holt S, Buckley H, Whelan S. The impact of exposure to domestic violence on children and young people: A review of the literature. Child Abuse \& Neglect. 2008; 32:797-810. [PubMed: 18752848]

Howard DE, Cross SI, Li X, Huang W. Parent-youth concordance regarding violence exposure: Relationship to youth psychosocial functioning. Journal of Adolescent Health. 1999; 25:396-406. [PubMed: 10608579]

Isreal P, Thomsen PH, Langeveld JH, Stormark KM. Parent-youth discrepancy in the assessment and treatment of youth in usual clinic care setting: Consequences to parent involvement. European Child \& Adolescent Psychiatry. 2007; 16:138-148. [PubMed: 17171574]

Jones DJ, Runyan D, Lewis T, Litrownik A, Black M, Wiley T, English D, Proctor L, Jones BL, Nagin D. Trajectories of childhood sexual abuse and early adolescent HIV/AIDS risk behavior: The role of other maltreatment, witnessed violence, and child gender. Journal of Clinical Child and Adolescent Psychology. 2010; 39:667-680. [PubMed: 20706919]

Kuo M, Mohler B, Raudenbush SL, Earls FJ. Assessing exposure to violence using multiple informants: Application of hierarchical linear modeling. Journal of Clinical Psychology and Psychiatry. 2000; 41:1049-1056.

Lewis T, Kotch J, Thompson R, Litrownik AJ, English DJ, Proctor LJ, Runyan DK, Dubowitz H. Witnessed violence and youth behavior problems: A multi-informant study. American Journal of Orthopsychiatry. 2010; 80:443-451. [PubMed: 20950286]

Lewis T, Kotch JB, Wiley TR, Litrownik AJ, English DJ, Thompson R, Zolotor A, Block S, Dubowitz $\mathrm{H}$. Internalizing problems: A potential pathway from child maltreatment to adolescent smoking. Journal of Adolescent Health. 2011; 48:247-252. [PubMed: 21338895]

Litrownik AJ, Newton R, Hunter W, English D, Everson MD. Exposure to family violence in young at-risk children: A longitudinal look at the effects of victimization and witnessed physical and psychological aggression. Journal of Family Violence. 2003; 18:59-73.

Hunter, WM.; Cox, CE.; Teagle, S.; Johnson, RM.; Mathew, R.; Knight, ED.; Leeb, RT.; Smith, JB., editors. LONGSCAN. Child's life events. Measures for assessment of functioning and outcomes in longitudinal research on child abuse: Volume 2: Middle childhood). 1992. Retrieved from http://www.iprc.unc.edu/longscan/pages/measures/Ages5to11/index.html 2003

Knight, ED.; Smith, JS.; Martin, LM.; Lewis, T., editors. LONGSCAN; The LONGSCAN Investigators. History of witnessed violence. Measures for assessment of functioning and 
outcomes in longitudinal research on child abuse: Volume 3: Early adolescence (ages 12-14). 1998. Retrieved from http://www.iprc.unc.edu/longscan/pages/measures/Ages12to14/index.html

Mahoney A, Donnelly WO, Boxer P, Lewis T. Marital and severe parent-to-adolescent physical aggression in clinic referred families: Mother and adolescent reports on cooccurrence and links to child behavior problems. Journal of Family Psychology. 2003; 17:3-19. [PubMed: 12666459]

Manly JT, Kim JE, Rogosch FA, Cicchetti D. Dimensions of child maltreatment and children's adjustment: Contributions of developmental timing and subtype. Developmental Psychopathology. 2001; 13(4):759-782.

Miller LS, Wasserman GA, Neugebauer R, Gorman-Smith D, Kamboukos D. Witnessed community violence and antisocial behavior in high-risk, urban boys. Journal of Clinical Child Psychology. 1999; 28:2-11. [PubMed: 10070603]

O'Leary K, Smith-Slep AM, O’Leary S. Co-occurrence of partner and parent aggression: Research and treatment implications. Behavior Therapy. 2000; 31:631-648.

Osofsky JD. Psychoanalytically based treatment for traumatized children and their families. Psychoanalytic Inquiry. 2003; 23:530-545.

Richters JE, Martinez P. Things I've seen and heard: An interview for young children about exposure to violence. 1990 Unpublished manuscript.

Runyan DK, Curtis P, Hunter W, Black MM, Kotch JB, Bangdiwala S, Dubowitz H. LONGSCAN: A consortium for longitudinal studies of maltreatment and the life course of children. Aggression and Violent Behavior. 1998; 3:275-285.

Srebnik D, Cauce AM, Baydar N. Help-seeking pathways for children and adolescents. Journal of Emotional and Behavioral Disorders. 1996; 4:210-221.

Thompson R, Dubowitz H, English DJ, Nooner KB, Wike T, Bangdiwala SI, Runyan DK, Briggs EC. Parents' and teachers' concordance with children's self-ratings of suicidality: Findings from a high-risk sample. Suicide and Life-Threatening Behavior. 2006; 36:167-181. [PubMed: 16704322]

Thompson R, Proctor LJ, English DJ, Narasimhan S, Everson M. Suicidal ideation in adolescence: Examining the role of recent adverse experiences. Journal of Adolescence. 2012; 35:175-186. [PubMed: 21481447]

Zinzow HM, Ruggiero KJ, Resnick H, Hanson R, Smith D, Saunders B, Kilpatrick D. Prevalence and mental health correlates of witnessed parental and community violence in a national sample of adolescents. Journal of Child Psychology and Psychiatry. 2009; 50(4):441-450. [PubMed: 19220624] 
Table 1

Distribution of Demographic Variables by Concordance Group

\begin{tabular}{llllc}
\hline & $\begin{array}{l}\text { Neither } \\
\text { Report } \\
(\mathbf{n = 3 9 2})\end{array}$ & $\begin{array}{l}\text { Both } \\
\text { Report } \\
(\mathbf{n}=\mathbf{5 8})\end{array}$ & $\begin{array}{l}\text { Parent } \\
\text { Only } \\
(\mathbf{n}=\mathbf{5 7})\end{array}$ & $\begin{array}{c}\text { Youth } \\
\text { Only } \\
(\mathbf{n}=\mathbf{2 5 9})\end{array}$ \\
\hline Youth Gender & \multicolumn{4}{c}{$\mathbf{\%}(\mathbf{n})$} \\
Female & $49(193)$ & $55(32)$ & $56(32)$ & $50(129)$ \\
Ethnicity & $68(265)$ & $74(43)$ & $67(38)$ & $82(212)$ \\
Non-White & & & & \\
Site & $15(60)$ & $24(14)$ & $14(8)$ & $33(85)$ \\
East & $15(60)$ & $10(6)$ & $14(8)$ & $15(38)$ \\
Midwest & $18(72)$ & $21(12)$ & $12(7)$ & $22(56)$ \\
South & $26(100)$ & $29(17)$ & $25(14)$ & $20(51)$ \\
Southwest & $26(100)$ & $16(9)$ & $35(20)$ & $11(29)$ \\
Northwest & $79(310)$ & $88(51)$ & $77(44)$ & $76(196)$ \\
\hline History of Maltreatment & & & & \\
\hline
\end{tabular}

Note. Column percentages add to $100 \%$ 


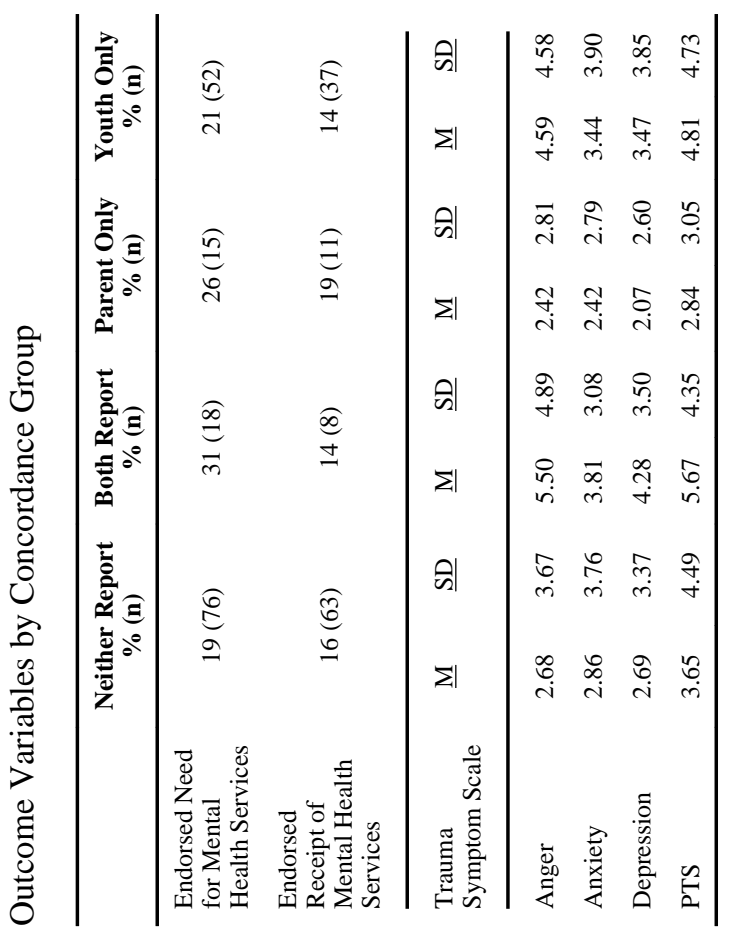




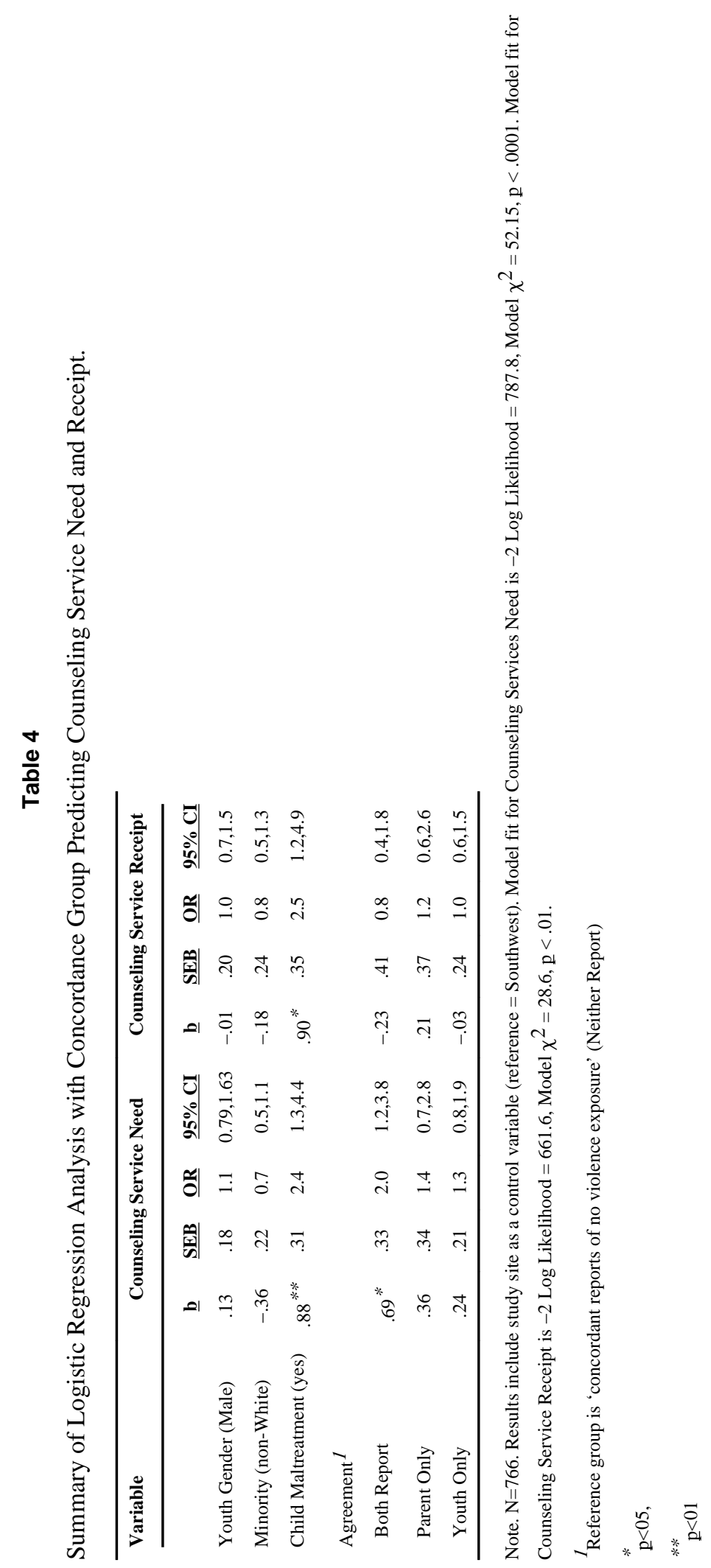

Child Abuse Negl. Author manuscript; available in PMC 2013 November 13. 